\title{
How Much Time Do Families Spend on the Health Care of Children with Diabetes?
}

Jane E. Miller · Colleen N. Nugent · Louise B. Russell

Received: April 11, 2016/ Published online: June 27, 2016

(C) The Author(s) 2016. This article is published with open access at Springerlink.com

\begin{abstract}
Introduction: Family time caring for children with diabetes is an overlooked component of the overall burden of the condition. We document and analyze risk factors for time family members spend providing health care at home and arranging/coordinating health care for children with diabetes.
\end{abstract}

Methods: Data for 755 diabetic children and 16,161 non-diabetic children whose chronic conditions required only prescription $(\mathrm{Rx})$

Enhanced content To view enhanced content for this article go to http://www.medengine.com/Redeem/ 3ED4F0605DE46151.

Electronic supplementary material The online version of this article (doi:10.1007/s13300-016-0181-z) contains supplementary material, which is available to authorized users.

J. E. Miller · C. N. Nugent $(\bowtie) \cdot$ L. B. Russell Institute for Health, Health Care Policy, and Aging Research, Rutgers University, New Brunswick, NJ, USA

e-mail: cnugent@ifh.rutgers.edu

J. E. Miller

Bloustein School of Planning and Public Policy, Rutgers University, New Brunswick, NJ, USA

L. B. Russell

Department of Economics, Rutgers University, New Brunswick, NJ, USA medication were from the 2009-2010 United States National Survey of Children with Special Health Care Needs (NS-CSHCN). We used generalized ordered logistic regressions to estimate adjusted odds ratios (AORs) of time burden by diabetes, insulin use, and stability of the child's health care needs, controlling for health and socioeconomic status.

Results: Nearly one-quarter of diabetic children had family members who spent $11+\mathrm{h} /$ week providing health care at home, and $8 \%$ spent $11+\mathrm{h} /$ week arranging/coordinating care, compared with $3.3 \%$ and $1.9 \%$, respectively, of non-diabetic Rx-only children. Time providing care at home for insulin-using children was concentrated in the higher time categories: AORs for insulin-using diabetic compared to non-diabetic Rx-only children were 4.4 for $1+$ $\mathrm{h}$ /week compared with $<1 \mathrm{~h} /$ week, 9.7 for $6+$ vs. $<6 \mathrm{~h}$, and 12.4 for $11+$ vs. $<11 \mathrm{~h}$ (all $P<0.05$ ); the pattern was less pronounced for non-insulin-using children. AORs for arranging/coordinating care did not vary by time contrast: $\mathrm{AOR}=4.2$ for insulin-using, 3.0 for non-insulin-using children.

Conclusion: Health care providers, school personnel, and policymakers need to work 
with family members to improve care coordination and identify other ways to reduce family time burdens caring for children with diabetes.

Keywords: Children; Care coordination; Diabetes; Family health; Stress; Time

\section{INTRODUCTION}

The prevalence of diabetes among United States (US) youth has risen rapidly in recent years; in 2009, more than 190,000 American youths had the condition [1]. Healthy People 2020, which sets national objectives for improving health in the US, states that the main diabetes-related goal is to reduce economic burden and improve quality of life [2]. In 2012, the monetary burden of diabetes in the US for children and adults was estimated at nearly $\$ 245$ billion including medical costs and the costs of disability, work loss, and premature death [3]. However, few studies have considered the time burden associated with diabetes-another important dimension of its overall economic burden.

Self-management of diabetes is important to minimize morbidity and mortality [3, 4], but is also time-consuming. Studies of adults have shown that self-care can require $2 \mathrm{~h}$ /day for those with established diabetes, longer for those inexperienced in self-care [5-7]. Almost 90\% of children in the US who have diabetes have type 1 [1], which requires careful coordination of blood glucose monitoring and insulin administration with dietary intake and physical activity to avoid hypoglycemic or hyperglycemic episodes [8]. For children with type 2 diabetes $[9,10]$, which is associated with obesity, management includes medication and monitoring diet and physical activity to promote a healthy weight [9]. Other necessary tasks for managing diabetes include arranging and keeping appointments with primary care providers, specialists, and diabetes educators [11].

For children with diabetes, these tasks must be done by family members. The time required can be substantial, and the effects on families include heavy time burdens, parental stress, family disruption, reductions in paid work, and financial strains [12-15]. Katz and colleagues [13] showed that three-quarters of families of children with type 1 diabetes reported a major impact, with more than a quarter spending at least $11 \mathrm{~h}$ /week providing or coordinating care, over a third restricting work or experiencing a financial impact, and more than $40 \%$ reporting annual medical expenses over $\$ 1000$. Studies of other conditions and health activities show that time is an important burden that can affect willingness and ability to undertake care [16-18].

Health care providers, health educators, school personnel, and policymakers have opportunities to coordinate efforts in order to reduce the time burdens of families with diabetic children and improve their well-being $[19,20]$. We use data from a nationally representative survey of the US to examine hours per week spent by family members providing health care for the child at home and arranging and coordinating his/her health care. We analyze time burdens by (1) whether or not the child uses insulin, (2) the stability of his/her health care needs, and (3) whether or not $\mathrm{s} /$ he has comorbid medical conditions. We look separately at time spent providing health care at home and time arranging/coordinating health care since these involve different tasks with different implications for reducing time burdens. We report results of multivariable analyses of ordered time categories (rather than dichotomizing time as previous studies 
have done) [13] to show the net effect of diabetes on family time, controlling for the child's health and sociodemographic characteristics.

\section{METHODS}

We use data from the 2009-2010 National Survey of Children with Special Health Care Needs (NS-CSHCN), a national, population-based survey conducted as part of the US State and Local Areas Integrated Telephone Survey $[21,22]$. The response rate was $43.7 \%$ for the landline sample, $15.2 \%$ for the cellphone sample, and $25.5 \%$ overall [21]. To be included in the sample, households had to have at least one child aged 17 years or younger with a special health care need ( $\mathrm{SHCN}$ ), as defined by the Child and Adolescent Health Measurement Initiative (CAHMI) CSHCN Screener [23]. Parents/guardians who were the most knowledgeable in the household about the child's health and care were asked whether the child had any of the following SHCNs: (1) used prescription ( $\mathrm{Rx}$ ) medications; (2) had elevated service use; (3) had functional limitations; (4) needed special therapies; (5) had emotional, developmental or behavioral problems. Children who met one or more of these criteria because of a medical, behavioral, or health condition that had lasted, or was expected to last, at least 12 months were classified as CSHCN. In households with more than one CSHCN, one such child was randomly selected.

The 2009-2010 NS-CSHCN included only children with at least one SHCN as identified by the CAHMI Screener. For comparison with children with diabetes, we used CSHCN who did not have diabetes and whose only SHCN was Rx medication. These "non-diabetic
Rx-only CSHCN" $(N=16,161)$ comprise the group with the lowest family time burden that is available in the 2009-2010 NS-CSHCN. This comparison group excludes non-diabetic CSHCN who needed special therapies, had elevated service use, had functional limitations, or had developmental or behavioral problems, all of whom have higher time burdens than the Rx-only group [24, 25]. We also present data for the "Referent Sample" of children without any SHCN $(N=4903)$ from the 2005-2006 NS-CSHCN, the most recent survey to ask about time providing and arranging/coordinating health care for children from the general US population [26].

\section{Diabetes Status}

Respondents were asked if the child currently had diabetes and, if so, whether the child used insulin. We excluded 38 cases who reported ever being told the child had diabetes but lacked current diabetes status and one case missing information on insulin use. The NS-CSHCN did not ask about diagnosis of type 1 or 2 diabetes, so we differentiate between insulin-using $(N=623)$ and non-insulin-using $(N=132)$ children with diabetes. Except for these exclusions, all children with diabetes were retained for analysis, including those who had other health conditions or health care needs, whether physical or emotional/behavioral, in addition to diabetes.

\section{Family Time Burden}

We analyzed three measures of family time burden: hours/week spent (1) providing health care for the child at home, (2) arranging or coordinating health care for the child, and (3) a combined measure of the two. Time providing 
care was collected by asking whether family members "provide health care at home such as changing bandages, care of feeding or breathing equipment, and giving medication and therapies" and, if so, how many hours per week. Arranging/coordinating care includes time family members spent "making appointments, making sure that care providers are exchanging information, and following up on their care needs" [27]. Responses were reported in the public use data as continuous hours/week up to 10 and categories of 11 to 20 and 21 or more. Because 0 and $<1 \mathrm{~h}$ /week were combined for arranging/coordinating care, we created four categories of hours/week for providing health care and arranging/ coordinating health care separately: none $/<1$, $1-5,6-10$, and $11+$. We also created a combined time measure categorized as defined in the note to Table 1.

\section{Control Variables}

Because the time burden is higher for families of less healthy children, and children with diabetes have worse health than those without the condition, we controlled for three measures of child's health: (1) stability of the child's health care needs, which were categorized in the public-use data as changing "all the time," "once in a while," "stable," or "none of the above" [27]; (2) comorbidity, measured by how many of 20 named health conditions, listed in Fig. 2, the CSHCN had; (3) activity limitations, which combine "how often" and "how much" the child's condition(s) affected daily activities: "consistently, often a great deal," "moderately, some of the time," or "never." We also controlled for the child's age, gender, race/ ethnicity, and family income, educational attainment, and urban/rural residence. The number of adults and of other CSHCN in the household were not associated with time burden [25]. We used imputed values from the NS-CSHCN public use data for missing information on family income, education, and race/ethnicity. Multivariable results did not differ according to whether imputed values were used [25]. Cases missing residence were included in a separate "missing" category for that variable. All variance inflation factors (VIFs) were below the cutoff of 2.5 used to identify problematic collinearity among covariates [28].

Our analyses include all children aged 0-17 years in the 2009-2010 NS-CSHCN who met the inclusion criteria for diagnosis (above) and had complete information on the covariates and time burden variables: providing health care for the child at home $(N=16,763)$, arranging/coordinating health care $(N=16,614)$, and combined time burden $(N=16,916)$.

\section{Statistical Methods}

Except as noted, all statistics for 2009-2010 were weighted to the national population of CSHCN using the child interview weights $[21,22]$. For the 2005-2006 survey, we used the referent sample weights [26]. Analyses were adjusted for the complex sample design using the svy commands with the subpop option in Stata 12.1 [29]. For each time burden outcome, we used multivariable regressions to estimate adjusted odds ratios (AORs) for children with diabetes compared to non-diabetic Rx-only CSHCN, controlling for the covariates listed above.

To test whether AORs were constant across time categories, we used Stata's gologit3 procedure with the autofit option to estimate generalized ordered logistic regressions, testing for non-proportionality using a Wald statistic 


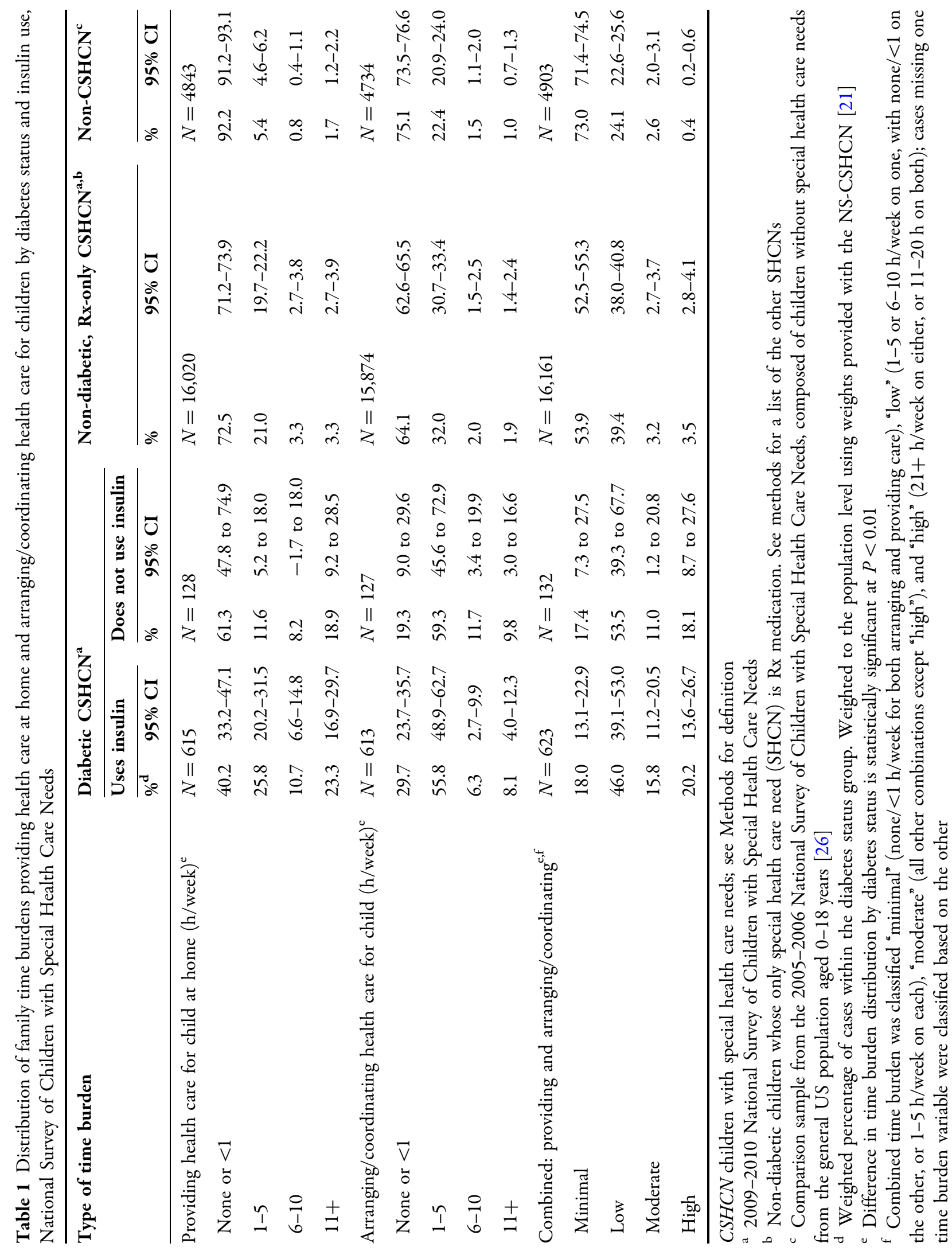


[30]. If proportionality was confirmed, a single AOR was estimated. If proportionality was violated, separate AORs were estimated for each time contrast [31]: $<1$ vs. $1+,<6$ vs. $6+$, and $<11$ vs. $11+\mathrm{h} /$ week to see whether time burdens were concentrated at lower or higher hours/week. Our final models are partial proportional odds, which specify uniform AORs when diabetes met proportionality at $P<0.01$ in exploratory analyses, but allow AORs to vary across levels of time burden when diabetes showed non-proportional odds [30].

\section{Compliance with Ethics Guidelines}

This article is based on analysis of data from previously conducted studies, the 2005-2006 and 2009-2010 US NS-CSHCN, and does not involve any new studies of human or animal subjects performed by any of the authors.

\section{RESULTS}

\section{Family Time Burden by Diabetes Status and Insulin Use}

Table 1 shows, for diabetic children and the comparison groups, the hours per week spent by families (1) providing health care for the child at home, (2) arranging and coordinating health care for the child, and (3) both combined. The first two columns of numbers are data for children with diabetes, subdivided by whether the child uses insulin or not. To the right of those columns the table presents data for two comparison groups of children: non-diabetic children in the 2009-2010 survey whose only SHCN was Rx medications ("non-diabetic Rx-only CSHCN", see "Methods") and children in the 2005-2006 NS-CSHCN from the general population of children (the "referent sample" of non-CSHCN, see "Methods").

The table shows that while Rx-only CSHCN without diabetes involve substantially lower family time burdens than children with diabetes, they require more time than children without SHCN. For combined time, for example, $73.0 \%$ of non-CSHCN required minimal time from family members for providing and arranging health care compared with $53.9 \%$ of non-diabetic Rx-only children. Therefore, contrasts of diabetic children with children from the general population, were such contrasts possible in the 2009-2010 survey, would show larger differences than those presented below. This should be kept in mind for the rest of the results, which compare diabetic children to non-diabetic Rx-only children.

Children with diabetes are more likely to require the highest time burdens from families providing health care for their child at home (Table 1). For example, insulin-using diabetic children were seven times as likely as Rx-only non-diabetic children to be in families spending $11+\mathrm{h}$ /week providing health care ( $23 \%$ vs. $3 \%)$. Time burdens were less if the diabetic child did not use insulin: although 19\% were in families spending $11+\mathrm{h}$ /week providing care, $61 \%$ were in families spending less than $1 \mathrm{~h} /$ week compared to $40 \%$ of those who used insulin.

High time burdens were less common for arranging and coordinating health care than for providing it, but insulin-using diabetic children were still four times as likely as non-diabetic Rx-only children to live in families that spent $11+\mathrm{h} /$ week on those tasks ( $8 \%$ vs. $2 \%$ ) while non-insulin-using diabetic children were five times as likely (10\% vs. $2 \%$ ). For combined time, providing health care at home dominated, and insulin-using diabetic children were concentrated in the higher time categories, 
with about a third facing moderate or high combined time burdens compared with $6 \%$ of non-diabetic Rx-only children's families.

\section{Time Burden by Child's Health}

Among children with diabetes, those with one or more other comorbid health conditions, which could be physical or emotional/ behavioral, were more likely than children with no other health conditions to have family members spend 6-10 h/week arranging/coordinating health care (not shown). Comorbidities were not associated with statistically significant differences in time providing health care at home.

Diabetic children whose health care needs changed all the time were nearly twice as likely as those with more stable health care needs to be in the moderate or high categories of combined family time arranging and providing care (Fig. 1). For instance, 32\% of those whose needs changed all the time were in the "high" combined time group compared to $18 \%$ and $17 \%$ of those whose needs "change once in a while" or are "usually stable," respectively. Within stability levels, children with diabetes had higher combined family time burdens than non-diabetic Rx-only children.

\section{Multivariable Regressions of Family Time Burden by Diabetes Status and Insulin Use}

Children with diabetes were more likely than non-diabetic Rx-only children to have unstable health care needs, comorbid health conditions, and activity limitations (Table S1 in the supplementary material). Although there were no statistically significant differences in socioeconomic characteristics between children with and without diabetes, non-insulin users were more likely than insulin-users to be

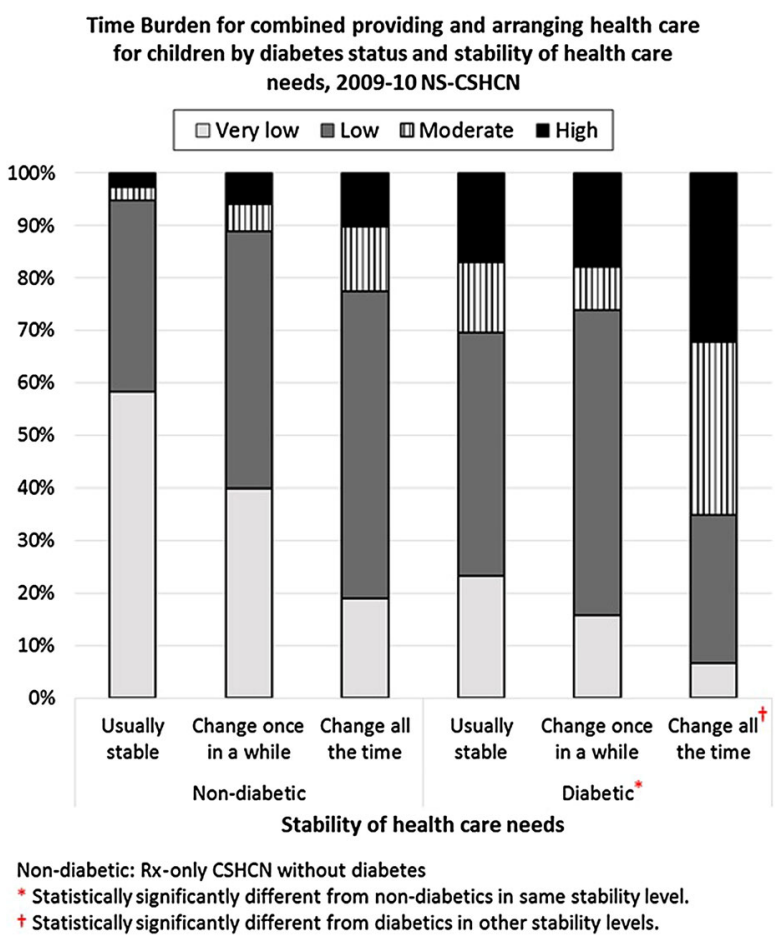

Fig. 1 Distribution of family time burden for combined providing and arranging health care for children with special health care needs by diabetes status and stability of health care needs, 2009-2010 NS-CSHCN. Weighted to the population level using weights provided with the 2009-2010 NS-CSHCN [21, 22]. NS-CSHCN National Survey of Children with Special Health Care Needs

non-Hispanic black, low-income, have less educated parents, and live in rural areas.

To estimate the effects of diabetes status and insulin use, net of these health and socioeconomic characteristics, we estimated generalized ordered logistic regressions for each type of time burden (Tables S2 and S3 in the supplementary material). AORs for all covariates and goodness-of-fit statistics for the multivariable models for each type of time burden are reported in the supplementary material. Subgroup sizes were not large enough to permit testing interactions between diabetes status/insulin use and stability of the child's health care needs in the multivariable specifications. 
AORs of time spent providing health care at home were non-proportional for both insulin-using and non-insulin-using children with diabetes compared with non-diabetic Rx-only CSHCN (Fig. 2). AORs of providing care for insulin-using diabetic children increased at higher time cutoffs from 4.4 for the comparison between $1+$ and $<1$ h per week to 9.8 for the $6+$ / $<6 \mathrm{~h}$ comparison and 12.4 for the $11+/<11 \mathrm{~h}$ comparison. These findings show a much higher concentration of diabetic children than

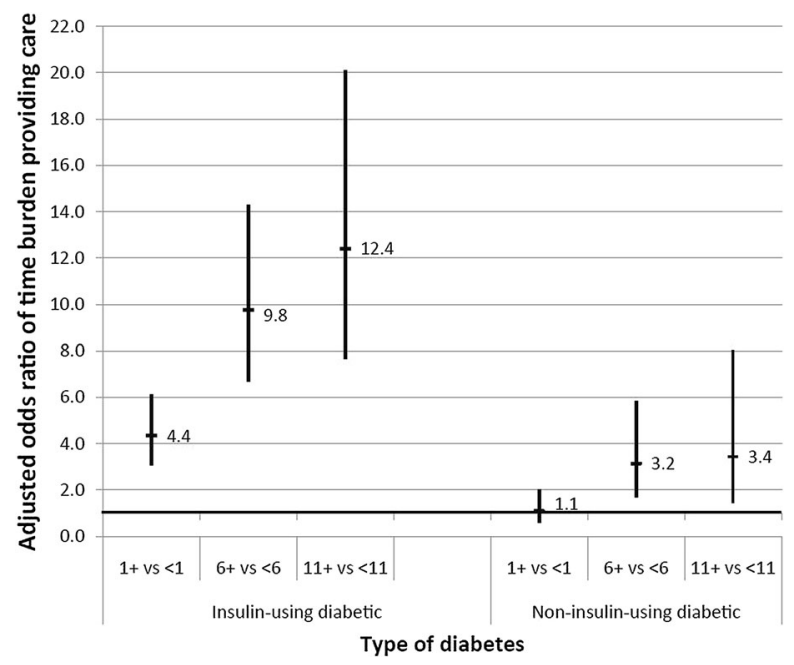

Fig. 2 Adjusted odds ratios and 95\% confidence intervals of time burden providing care for the child at home by diabetes status and insulin use, 2009-2010 NS-CSHCN. Compared to non-diabetic Rx-only CSHCN. Weighted to the population level using weights provided with the 2009-2010 NS-CSHCN [21, 22]. Odds ratios are adjusted for three measures of child's health (stability of child's health care needs, number of named health conditions child has, and activity limitations), child's age, gender, and race/ethnicity, family income, education, and urban/rural residence (see "Methods" section). Named health conditions asked about on the NS-CSHCN included: ADHD, allergies, anxiety, arthritis, asthma, autism, behavior problems, blood problems, cerebral palsy, cystic fibrosis, depression, developmental delays, diabetes, Down syndrome, epilepsy, heart problems, intellectual disability, migraines, muscular dystrophy, and traumatic brain injury. A child in the CSHCN sample could have conditions other than those named on the questionnaire. NS-CSHCN National Survey of Children with Special Health Care Needs non-diabetic Rx-only children in the highest category of time providing health care at home.

For non-insulin-using diabetics, AORs for providing care rose from 1.1 to 3.2 to 3.4 for the same time cutoffs. For each time contrast, the AORs were substantially and statistically significantly higher for insulin-using than for non-insulin-using children with diabetes. The AORs for $6+$ and $11+\mathrm{h}$ /week were statistically significantly higher than for the $1+\mathrm{h}$ /week contrast in each diabetes group, but not statistically different from one another.

For arranging/coordinating care, children with diabetes had substantially higher odds of moderate or high family time burdens than non-diabetic Rx-only CSHCN: $\mathrm{AOR}=4.2$ for insulin-using and $\mathrm{AOR}=3.0 \quad$ for non-insulin-using children with diabetes (Fig. 3). The corresponding AORs for combined

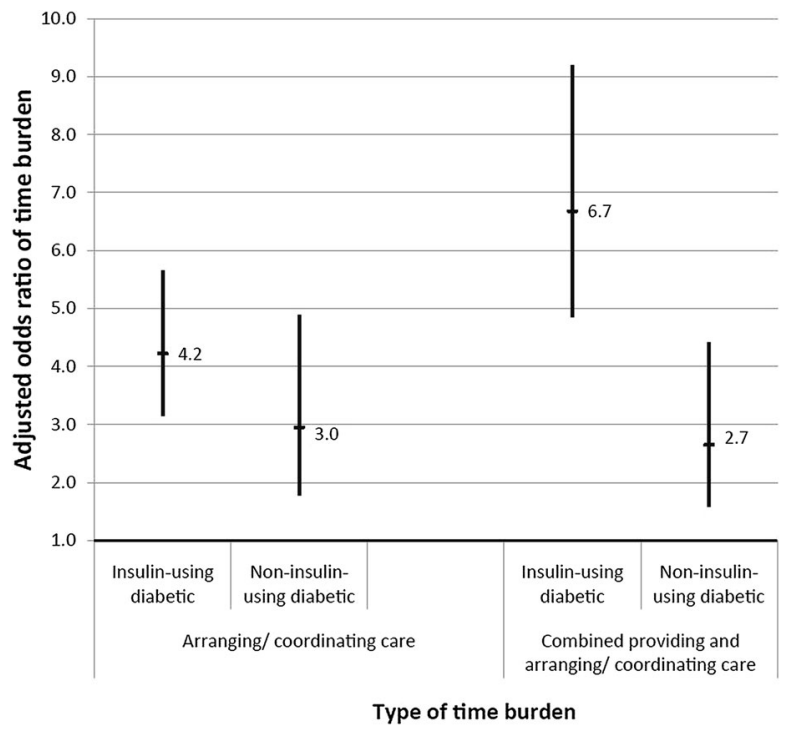

Fig. 3 Adjusted odds ratios and 95\% confidence intervals of time burden associated with health care for children by diabetes status, insulin use, and type of time burden, 2009-2010 NS-CSHCN. Compared to non-diabetic $\mathrm{Rx}$-only CSHCN. Weighted to the population level using weights provided with the 2009-2010 NS-CSHCN $[21,22]$. Controlling for all variables listed in note to Fig. 2. NS-CSHCN National Survey of Children with Special Health Care Needs 
time were 6.7 and 2.7. In both cases the AORs were constant across time contrasts (proportional odds).

\section{DISCUSSION}

Our analyses of data for the US show that families of children with diabetes spend substantial time providing health care for their children at home and arranging/coordinating their health care. More than one-fifth of insulin-using diabetic children had family members that spent 11 or more hours/week providing health care at home compared to $3 \%$ of non-diabetic Rx-only children-the CSHCN with the least complex health care needs. In addition, almost one in ten diabetic children were in families that spent 11 or more hours/ week arranging and coordinating health care for their children compared with $2 \%$ of non-diabetic Rx-only children. These time burdens are ongoing for a decade or more until the child is old enough to manage his/ her own diabetes care [32-34] and are in addition to the time spent on routine parental tasks, including feeding, bathing, and supervising homework and bedtime [35].

Not surprisingly, given the additional tasks of monitoring blood sugar, administering insulin, and coordinating food intake and physical activity with insulin [34], time burdens are greater for families of insulin-using children with diabetes than for those who do not use insulin. Nearly $60 \%$ of insulin-using diabetics have family members who spend more than an hour per week providing health care at home compared with fewer than $40 \%$ of non-insulin-using diabetics. The extra burdens involved in arranging and coordinating health care for children with diabetes are similar whether the child uses insulin or not, with $70 \%$ to $80 \%$ having family members spend an hour or more per week on these tasks. The lack of difference between diabetic children using insulin and those not using insulin makes sense given that arranging and coordinating care involve tasks such as making appointments and making sure that care providers are exchanging information, which are not related to insulin use. These patterns persist even when other factors associated with elevated family time burdens, such as poor child health and low socioeconomic status, are taken into account.

Unstable health care needs further exacerbate the time burden on families of children with diabetes: Nearly two-thirds of those whose needs change all of the time required moderate to high combined time providing and arranging care, vs. one-quarter to one-third of those with more stable needs. Unstable needs may reflect a more severe diagnosis or more recent diagnosis for which good control has yet to be established. Moreover, families of children recently diagnosed with diabetes are still identifying the child's team of health care providers, learning to manage the condition, and starting to coordinate care across providers-a time-consuming set of new tasks to master [9].

This study has several strengths. First, this article documents the substantial time spent by family members on tasks related to providing health care at home and arranging/ coordinating health care for children with diabetes, helping to build the case for devoting more attention to these issues. Second, unlike most clinical studies, the NS-CSHCN provides a large national sample that includes enough children with diabetes to permit comparison of those who use insulin and those who do not and to examine patterns by comorbidity and stability of the child's health care needs. Third, our analyses revealed that both insulin-using 
and non-insulin-using diabetics are concentrated in the higher time categories $(6+$ $\mathrm{h}$ /week) of care provided at home by family members, a finding obscured in previous studies that defined dichotomous indicators of time [13]. Finally, the 2009-2010 NS-CSHCN improved upon representativeness compared to previous rounds by including both landlines and cellphones [36].

This study also has limitations related to the fact that the NS-CSHCN was not a study of diabetes per se. First, the survey did not ask directly about type 1 and type 2 diabetes, so we approximated those classifications based on insulin use, which shows a strong association with time burden. Second, the question about time arranging/coordinating health care for the child did not specify whom to include; we do not know whether respondents only considered coordinating with providers in the formal health care sector or also included caregivers at school and after-school programs such as school nurses, dieticians, and teachers. For children with diabetes, these people are an integral part of the team that helps manage their condition. Third, respondents reported time they or other family members spent providing or arranging care, so some gave proxy reports, which may be less accurate than reports by the family member him/herself. Time estimates might also be affected by recall bias. Furthermore, it is not clear whether the time reported as spent by "parents or other family members" providing care at home also includes time spent by the child him/herself, which previous studies have shown to be substantial among children with diabetes [14].

Total time is also understated because time spent with the child at appointments, including travel and waiting time, is not included. Studies of adults show these activities require substantial time [37]. In addition, the questions about time spent providing and arranging care are not specific to diabetes care and therefore do not provide detail about the reasons for the greater amount of time spent by families of children with diabetes or why time spent by diabetic children using insulin was greater than that for those who do not use insulin. Finally, the reference group in our analysis is non-diabetic children whose only SHCN is $\mathrm{Rx}$ medication-those in the 2009-2010 NS-CSHCN with the least complex health care needs. Comparison against non-CSHCN from the 2005-2006 NS-CSHCN, the most recent to include children from the general US population, suggests that our multivariable results understate the extra time spent by families of children with diabetes compared to families of children without chronic health conditions.

The mission of the Center for Disease Control's Division for Diabetes Translation is "to reduce the preventable burden of diabetes through public health leadership, partnership, research, programs, and policies that translate science into practice" [38]. That mission suggests important roles for health care providers in helping families with children with diabetes cope with the time burdens involved in providing health care for the child at home and arranging/coordinating his/her care. Although health care providers already work with both parents and children to provide correct information about diabetes management and ensure that they can execute self-care tasks properly, Ziaian et al. [14] found that children with diabetes reported an average of more than six treatment tasks per day, taking nearly an hour of their time daily in addition to a $1 / 2 \mathrm{~h}$ of their parents' time. Hence, an important focus for providers and diabetes educators is teaching children to assume self-care tasks as they grow older while 
maintaining parental involvement to ensure good metabolic control, following age-specific guidelines based on physical, emotional, and cognitive skills [32].

Future research could explore which tasks are most time-consuming and whether the family time burden can be reduced through use of technologies such as insulin pumps, continuous glucose monitoring, or educating older diabetic children to participate even more in their own care. Given that the burden of self-care of diabetes is substantial even for adults [5, 39], perhaps improving diabetes management for youth via such mechanisms at age-appropriate levels can reduce the time burden of self-care for adults further down the road.

Studies have found that lack of coordination among health care providers, and between providers and community institutions, interferes with implementation of good diabetes care [19, 40]. Children spend a considerable amount of waking time at school and in after-school programs, which suggests that the time required by school staff to provide and supervise care for diabetic children may be substantial. Physicians, nurses, school personnel, and health educators can work to improve coordination among all parties involved in overseeing and providing the child's day-to-day diabetes care. Policymakers can help by promoting medical homes [13, 41], which can assist with arranging/coordinating health care for children with diabetes. They can also work to broaden health insurance to cover services needed by children with diabetes, which reduces the financial impact [15] and time burden for families of children with chronic illnesses [25]. Finally, because diabetes management requires doing tasks throughout the day, coordination among families, primary care providers, specialists, schools, and other caregivers is a major issue, but unfortunately not well addressed by mechanisms within the health care system. Health care providers are well positioned to take a leadership role in developing and implementing changes to improve care coordination to help reduce strains on families of children with diabetes.

\section{CONCLUSION}

Families of children with diabetes spend substantial time providing health care at home and arranging/coordinating health care for their children, especially younger children and those who use insulin. Substantially more time is spent by families of diabetic children than those of children with many other chronic conditions, contributing to the family strains identified by past studies. Families are key to the successful management of diabetes in children, and many families of diabetic children would benefit from help reducing this family time burden. Coordination among health care providers, and between health care providers and school personnel for diabetic children of school age could be especially important to explore as a way to reduce time burden for both families and school staff while improving children's levels of diabetic control.

\section{ACKNOWLEDGMENTS}

No funding or sponsorship was received for this study or publication of this article. All named authors meet the International Committee of Medical Journal Editors (ICMJE) criteria for authorship for this manuscript, take responsibility for the integrity of the work as a whole, and have given final approval to the version to be published. We would like to thank Stephen Blumberg, PhD, and Matthew Bramlett, PhD, of the National Center for 
Health Statistics for guidance about the NS-CSHCN, and Monika Safford, MD, of the University of Alabama-Birmingham for advice on issues related to diabetes care.

Disclosures. Jane E. Miller, Colleen N. Nugent, and Louise B. Russell declare that they have no conflict of interest.

Compliance with Ethics Guidelines. The data are from a de-identified public use data set, so we did not submit it to review by a human subjects review board. For this type of study formal consent is not required.

Open Access. This article is distributed under the terms of the Creative Commons Attribution-NonCommercial 4.0 International License (http://creativecommons.org/licenses/ by-nc/4.0/), which permits any noncommercial use, distribution, and reproduction in any medium, provided you give appropriate credit to the original author(s) and the source, provide a link to the Creative Commons license, and indicate if changes were made.

\section{REFERENCES}

1. Pettitt DJ, Talton J, Dabelea D, SEARCH for Diabetes in Youth Study Group, et al. Prevalence of diabetes in US youth in 2009: the SEARCH for Diabetes in Youth Study. Diabetes Care. Diabetes Care. 2014;37:402-8.

2. Healthy People 2020. 2020 topics and objectives: diabetes; 2015. http://www.healthypeople.gov/ 2020/topics-objectives/topic/diabetes. Accessed 10 Dec 2015.

3. Centers for Disease Control and Prevention. National diabetes statistics report: Estimates of diabetes and its burden in the United States, 2014. Atlanta: US Department of Health and Human Services; 2014.

4. Brownson CA, Heisler M. The role of peer support in diabetes care and self-management. Patient. 2009;2:5-17.
5. Russell LB, Suh D, Safford MM. Time requirements for diabetes self-management: too much for many? J Fam Pract. 2005;54:52-6.

6. Safford MM, Russell L, Suh D, Roman S, Pogach L. How much time do patients with diabetes spend on self-care? J Am Board Fam Pract. 2005;18:262-70.

7. Jowsey T, Yen L, PM W. Time spent on health related activities associated with chronic illness: a scoping literature review. BMC Public Health. 2012;12:1044-2458.

8. Siminerio LM, Albanese-O'Neill A, Chiang JL, et al. Care of young children with diabetes in the child care setting: a position statement of the American Diabetes Association. Diabetes Care. 2014;37: 2834-42.

9. Copeland KC, Silverstein J, Moore KR, et al. American Academy of Pediatrics. Management of newly diagnosed type 2 Diabetes Mellitus (T2DM) in children and adolescents. Pediatrics. 2013;131:364-82.

10. Lawrence JM, Imperatore G, Dabelea D, SEARCH for Diabetes in Youth Study Group, et al. Trends in incidence of type 1 diabetes among non-Hispanic white youth in the US, 2002-2009. Diabetes. 2014;63:3938-45.

11. American Diabetes Association. Standards of medical care in diabetes-2014. Diabetes Care. 2014;37(Suppl 1):S14-80.

12. Haugstvedt A, Wentzel-Larsen T, Rokne B, et al. Perceived family burden and emotional distress: similarities and differences between mothers and fathers of children with type 1 diabetes in a population-based study. Pediatr Diabetes. 2011;12:107-14.

13. Katz ML, Laffel LM, Perrin JM, Kuhlthau K. Impact of type 1 diabetes mellitus on the family is reduced with the medical home, care coordination, and family-centered care. J Pediatr. 2012;160:861-7.

14. Ziaian T, Sawyer MG, Reynolds KE, et al. Treatment burden and health-related quality of life of children with diabetes, cystic fibrosis and asthma. J Paediatr Child Health. 2006;42:596-600.

15. Songer TJ, LaPorte R, Lave JR, et al. Health insurance and the financial impact of IDDM in families with a child with IDDM. Diabetes Care. 1997;20:577-84.

16. Russell LB, Ibuka Y, Abraham KG. Health-related activities in the American Time Use Survey. Med Care. 2007;45:680-5.

17. Russell LB. Completing costs: patients' time. Med Care. 2009;47:S89-93. 
18. Wittenberg E, Saada A, Prosser LA. How illness affects family members: a qualitative interview survey. Patient. 2013;6:257-68.

19. Appiah B, Hong Y, Ory MG, et al. Challenges and opportunities for implementing diabetes self-management guidelines. J Am Board Fam Med. 2013;26:90-2.

20. Saint Louis C. Many schools failing on type 1 diabetes care. New York Times; Oct 26, 2015. http:// www.nytimes.com/2015/10/27/health/many-schoolsfailing-on-diabetes-care.html?_r=0. Accessed 15 Sep 2015.

21. Bramlett $\mathrm{MD}$, Blumberg SJ, Ormson $\mathrm{AE}$, et al. Design and operation of the National Survey of Children with Special Health Care Needs, 2009-2010. Vital Health Stat 1. 2014;57:1-282.

22. Maternal and Child Health Bureau, National Center for Health Statistics. 2009-2010 National Survey of Children with Special Health Care Needs 2012. http://www.cdc.gov/nchs/slaits/cshcn.htm. Accessed 10 Dec 2015.

23. CAHMI-The Child and Adolescent Health Measurement Initiative. The Children with Special Health Care Needs (CSHCN) Screener. http://www. cahmi.org/projects/children-with-special-healthcare-needs-screener/. Accessed 15 Sep 2015.

24. Bramlett M, Read D, Bethell C, Blumberg S. Differentiating subgroups of children with special health care needs by health status and complexity of health care needs. Matern Child Health J. 2009;13:151-63.

25. Miller JE, Nugent CN, Russell LB. Risk factors for family time burdens arranging and providing health care for children with special health care needs: lessons from nonproportional odds models. Soc Sci Res. 2015;52:602-14.

26. Blumberg S, Welch E, Chowdhury S, et al. Design and operation of the National Survey of Children with Special Health Care Needs, 2005-2006. Vital Health Stat 1. 2008.

27. National Center for Health Statistics. 2009-2010 National survey of children with special health care needs questionnaire, December 14, 2011 version 2011. http://www.cdc.gov/nchs/slaits/cshcn.htm. Accessed 15 Sep 2015.

28. Allison PD. Multiple regression: a primer. Thousand Oaks: Pine Forge Press; 1999.

29. StataCorp. Stata Statistical Software: Release 12.1 2011.
30. Williams R. Generalized ordered logit/partial proportional odds models for ordinal dependent variables. Stata J. 2006;6:58-82.

31. Fu V. Estimating generalized ordered logit models. Stata Tech Bull Repr. 1998;8:160-4.

32. Kohler E, Hurwitz LS, Milan D. A developmentally staged curriculum for teaching self-care to the child with insulin-dependent diabetes mellitus. Diabetes Care. 1982;5:300-4.

33. Silverstein J, Klingensmith G, Copeland $\mathrm{K}$, et al Care of children and adolescents with type 1 diabetes: a statement of the American Diabetes Association. Diabetes Care. 2005;28:186-212.

34. Naughton MJ, Joyce P, Morgan TM, SEARCH for Diabetes in Youth Study Group, et al. Longitudinal associations between sex, diabetes self-care, and health-related quality of life among youth with type 1 or type 2 diabetes mellitus. J Pediatr. 2014;164(1376-1383):e1.

35. Strazdins L, Welsh J, Korda R, et al. Not all hours are equal: could time be a social determinant of health? Sociol Health Illn. 2015;38(1):21-42.

36. Centers for Disease Control and Prevention, National Center for Health Statistics. 2009-2010 National survey of children with special health care needs frequently asked questions. 2011. http:// www.cdc.gov/nchs/slaits/cshcn.htm. Accessed 15 Sep 2015.

37. Russell LB, Ibuka Y, Carr D. How much time do patients spend on outpatient visits? The American Time Use Survey. Patient. 2008;1:211-22.

38. Centers for Disease Control and Prevention. About CDC's Division of Diabetes Translation; 2015. http://www.cdc.gov/diabetes/about/index.html. Accessed 10 Dec 2015.

39. Yen LE, McRae IS, Jowsey T, et al. Time spent on health related activity by older Australians with diabetes. J Diabetes Metab Disord. 2013;12:1.

40. Purnell TS, Lynch TJ, Bone L, et al. Perceived barriers and potential strategies to improve self-management among adults with Type 2 diabetes: a community-engaged research approach. Patient. 2016:1-10. doi:10.1007/ s40271-016-0162-3.

41. Miller JE, Nugent CN, Russell LB. Which components of medical homes reduce the time burden on families of children with special health care needs? Health Serv Res. 2014;50:440-61. 